\title{
The treatment of microbubble disease
} of 20th century cellulose acetate microfilm: application of ethyl cellulose and microrepair method

\author{
Zhihui Jia*, Jing Li, Yuhu Li, Yunpeng Qi, Daodao Hu, Huiping Xing and Xiaolian Chao
}

\begin{abstract}
Microbubble disease observed in cellulose acetate microfilm is accompanied by the production of vinegar syndrome, which affects the image integrity. In the present study, samples of cellulose acetate microfilm with microbubble disease were selected to investigate potential treatment methods. Samples were sourced from the Republic of China (AD 1912-1949) microfilm collections held in the Second Historical Archives of China. A combination of optical microscopy and a stainless-steel needle was used to remove plasticizer exudation within microbubbles. The plasticizer was effectively removed by infiltrating butan-1-ol into the microbubble from a small hole made by the stainless-steel needle. SEM and confocal microscopy were used to study the morphology and roughness of the internal surface of the microbubbles. It was found that the blurry image could be attributed to light scattering from the rough surface. Ethyl cellulose was used to fill the interior of the microbubble to obtain a clearer image. To determine the protective potential of this filling material, the chemical and mechanical properties of coated film after dry heat, hygrothermal and UV accelerated ageing were measured. Based on the above-mentioned results, it is encouraging that a new microrepair method and its corresponding method are offered in film treatment work.
\end{abstract}

Keywords: Cellulose acetate film, Microbubble, Plasticizer exudation, Microrepair technique, Ethyl cellulose

\section{Introduction}

Cellulose acetate (CA) was regarded to be a versatile material, particularly at the beginning of the twentieth century, as it was a safer alternative to the highly flammable cellulose nitrate used in textiles, food, tool handles, and so on [1-3]. Its most significant application was as a photographic film base $[4,5]$. The stability of cellulose acetate film is affected by the chemical properties of the material and its preservation environment, a major cause of deterioration attributed to hydrolysis of the ester side chain leading to deacylation [6,7]. This process releases acetic acid, its concentration increasing within the tightly

\footnotetext{
*Correspondence: jzh1988@snnu.edu.cn; liyuhu@snnu.edu.cn School of Materials Science and Engineering, Engineering Research Center of Historical Cultural Heritage Conservation, Ministry of Education, Shaanxi Normal University, Xi'an 710119, Shaanxi, China
}

sealed cases, the hydrolysis reaction becoming autocatalytic [8-10]. Another contributing deterioration factor is plasticizer migration, the presence of white crystals on the substrate surface are observed when the plasticizer moves towards the substrate [11-14]. The white spots, also known as microbubble disease, are observed when the plasticizer moves towards the image layer.

Recently, we have studied the causes of microbubble diseases of cellulose acetate microfilm located in the collections of the Second Historical Archives of China [15]. The results showed that microbubble disease is accompanied by the production of vinegar syndrome. Microbubbles of different shapes and sizes are mainly produced between the protective and emulsion layers. The crystals inside the microbubbles were found to be plasticizer and resulted in the image appearing blurry, significantly
Springer Open

(c) The Author(s) 2020. This article is licensed under a Creative Commons Attribution 4.0 International License, which permits use, sharing, adaptation, distribution and reproduction in any medium or format, as long as you give appropriate credit to the original author(s) and the source, provide a link to the Creative Commons licence, and indicate if changes were made. The images or other third party material in this article are included in the article's Creative Commons licence, unless indicated otherwise in a credit line to the material. If material is not included in the article's Creative Commons licence and your intended use is not permitted by statutory regulation or exceeds the permitted use, you will need to obtain permission directly from the copyright holder. To view a copy of this licence, visit http://creativeco mmons.org/licenses/by/4.0/. The Creative Commons Public Domain Dedication waiver (http://creativecommons.org/publicdomain/ zero/1.0/) applies to the data made available in this article, unless otherwise stated in a credit line to the data. 
affects the integrity of the image. Therefore, it is essential to develop a new treatment method to improve the integrity of the images for samples that have microbubble disease.

Conservation based on physics and chemical strategies is expected to be a solution for the protection of cellulose acetate film. Melville et al. has proposed the most basic theoretical knowledge of film protection and has been broadly used in the archives, libraries, and museums [16, 17]. In addition, digital restoration technology favored by film collectors is a safe and reliable repair method [18-20]. However, the image and film lifetime will not be effectively protected if the disease is not treated prior to digital restoration. In terms of this issue, our group has undertaken research into the vinegar syndrome of cellulose acetate film [21-23], and found that the crystals on the surface of cellulose acetate film can be effectively removed $[24,25]$. However, removal of plasticizer from within a microbubble is poorly understood. The small size and closed nature of microbubbles means that they are unable to be repaired by conventional methods.

The object of this study is to explore an effective method for treating microbubble disease to better protect cellulose acetate film. Cellulose acetate film samples with microbubble disease were chosen from the Republic of China (AD 1912-1949) microfilm collections held in the Second Historical Archives of China. This paper discusses a new methodology using optical microscopy combined with a stainless-steel needle to remove plasticizer from microbubbles. Scanning electron microscopy (SEM) and confocal microscopy are used to study morphology and roughness of the internal surface of microbubble.

The effect of filling empty microbubbles with ethyl cellulose to obtain a clearer image will be investigated. As a semi-crystalline cellulose polymer derivative, ethyl cellulose (EC) has the characteristics of being odorless, non-toxic and physiological stable. EC is broadly used in a variety of industrial applications and is generally regarded as being safe (Generally Recognized As Safe, GRAS) [26]. Commercial version of EC has good solubility and superior performance, such as mechanical strength, light resistance, durability, excellent elasticity over a wide temperature range [27-29]. The proposed use of EC as a filling material is also based on its functions of adhesion, filling, film formation. To determine the protective potential of this filling materials, the tensile strength, folding endurance and optical density of coated film after dry heat, hygrothermal and UV accelerated ageing will be assessed.

\section{Experimental}

\section{Sample description}

Two rolls of cellulose acetate microfilms of the Republic of China (1946) in the collections of the Second Historical Archives of China were selected in this study. These microfilms recorded China's diplomacy during the republic of China and are very valuable cultural relics. One roll exhibits no microbubbles and serves as a reference, Fig. 1a, and in the second film the white microbubbles are observed throughout the sample, Fig. 1b.

\section{Materials}

All reagents used were of analytical grade from Aladdin (China) and used as received. $45 \mathrm{cP}$ (ETHOCEL Std 45 Premim) EC with ethoxy content of 48.0-49.5\% (degree of substitution of $\sim 2.5$ ) was used as a filling material. Butan-1-ol was selected as the solvent. Stainless steel needles, acupuncture needles $(0.18 \times 25 \mathrm{~mm})$, were bought at a drugstore.

\section{Removing plasticizers in microbubbles}

In order to improve the integrity of the image, the crystals inside the microbubble were removed. The film was placed in an optical microscope (XWY-VI Fiber analyzer) with the image layer facing up. The process of removing
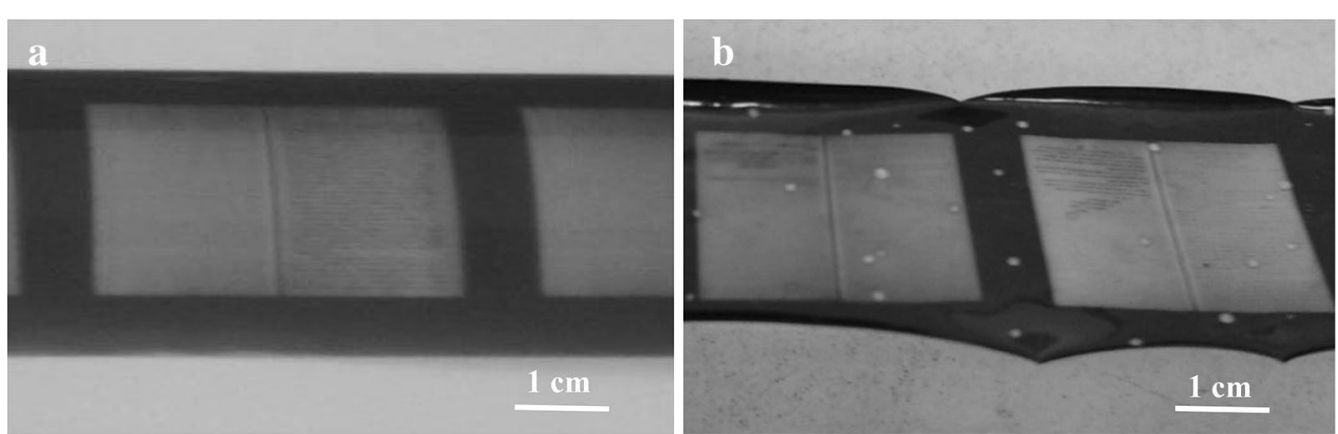

Fig. 1 Cellulose acetate microfilm of the Republic of China (1946) in the collections of the Second Historical Archives of China: samples a without and $\mathbf{b}$ with microbubbles disease 
the plasticizers from within a microbubble was as follows (Fig. 2): (1) the microbubble was located and placed in the center of the field of view; (2) a cotton swab dipped into a butan-1-ol solution was wiped over the surface [25]; (3) a stainless steel needle punctured the protective coating of the microbubble, and the plasticizer removed from inside the microbubble by repeatedly dipping a cotton swab into a butan-1-ol solution and swabbing and pressing the protective layer of microbubble; (4) the cleaning agent was removed using filter paper held next to the microbubble edge and dried in natural conditions.

\section{Conservation procedure and characterization methods}

To prepare ethyl cellulose solutions of varying concentration: different masses of EC (3, 5, 7 and $10 \mathrm{~g})$ were added to a round bottom three-mouth flask containing different masses butan-1-ol (97, 95, 93 and $90 \mathrm{~g})$, followed by heating reflux $\left(120^{\circ} \mathrm{C}, 2 \mathrm{~h}\right)$. The butan-1-ol solutions with $\omega .3 \%, \omega .5 \%, \omega .7 \%$ and $\omega .10 \%$ of EC were obtained and used as filling materials to permeate into the microbubbles according to method displayed in Fig. 2.

The edge of two pieces of film with microbubbles $\left(\sim 5 \times 5 \mathrm{~mm}^{2}\right)$ which contained no image were selected for treatment. The plasticizer was removed from a microbubble and a w. 5\% EC butan-1-ol solution was applied to one film sampled as illustrated in Fig. 2. The protective microbubble layer was removed by a scalpel and the internal surface morphology of the film was analyzed by scanning electron microscopy. The sample was placed image layer facing up on aluminum SEM specimen holders and held in place with sticky tape. Several coupons were examined using a Hitachi SU3500 SEM. Analyses were performed at low vacuum (1-150 Pa), with an accelerating voltage of $5 \mathrm{kV}$ and a magnification of $40 \times$. Samples were also placed on aluminum specimen holders using double-sided sticky tape with image layer facing up for confocal microscopy (Keyence VK-X250K).
The 3D morphology of the sample surface was analyzed using a $20 \times$ optical lens. Surface roughness parameters were obtained using the software VK-H1XAC according to ISO 25,178-2: 2012, such as $\mathrm{S}_{\mathrm{a}}, \mathrm{S}_{\mathrm{z}}, \mathrm{S}_{\mathrm{tr}}, \mathrm{S}_{\mathrm{pc}}, \mathrm{S}_{\mathrm{dr}}$. Reflectance spectra of the internal surface of the microbubble after cleaning and filling were recorded in the range of 400-700 nm using a multi-angle spectrophotometer (MA98, X-Rite, USA) with the colorimetric illuminant of D65.

In order to study durability of filling materials, the treated specimens (Cellulose acetate film from the China Film Archive) were prepared as follows. The film was dipped into a 5\% sodium hypochlorite solution for $1 \mathrm{~min}$, then the image layer of the film was removed by rinsing with distilled water, and placed it at ambient temperature until dry. The filling material was evenly coated on the surface of the substrate, then left to dry at room temperature, a $5 \%$ aqueous gelatin solution was coated on the surface of the filling agent and allowed to air dry. Comparative study with uncoated samples were performed. The mechanical properties of the specimens were investigated using a control universal material tester fitted with a $50 \mathrm{~N}$ load cell for tensile testing, equipped with pneumatic grips with $25 \mathrm{~mm}$ gauge length, operating at a cross head speed of $250 \mathrm{~mm} / \mathrm{min}$, alongside with long axis in the film transverse direction. Film samples were cut into $22 \times 200 \mathrm{~mm}$ strips as per the ASTM D882 test method. Folding endurance tests on specimens were performed using a Schopper type folding endurance tester and the applied force was $7.5 \mathrm{~N}$ according to GB/T 9858-1988. The film optical density was tested using a table type transmission density meter. All mechanical testing was performed at least 20 samples and the reported values were calculated as average \pm 1 standard deviation.

Artificial accelerated aging tests were performed using Shanghai Huitai Aging Test Chamber BH0-402A at $105^{\circ} \mathrm{C}$ for 21 days. Hygrothermal accelerated aging of the

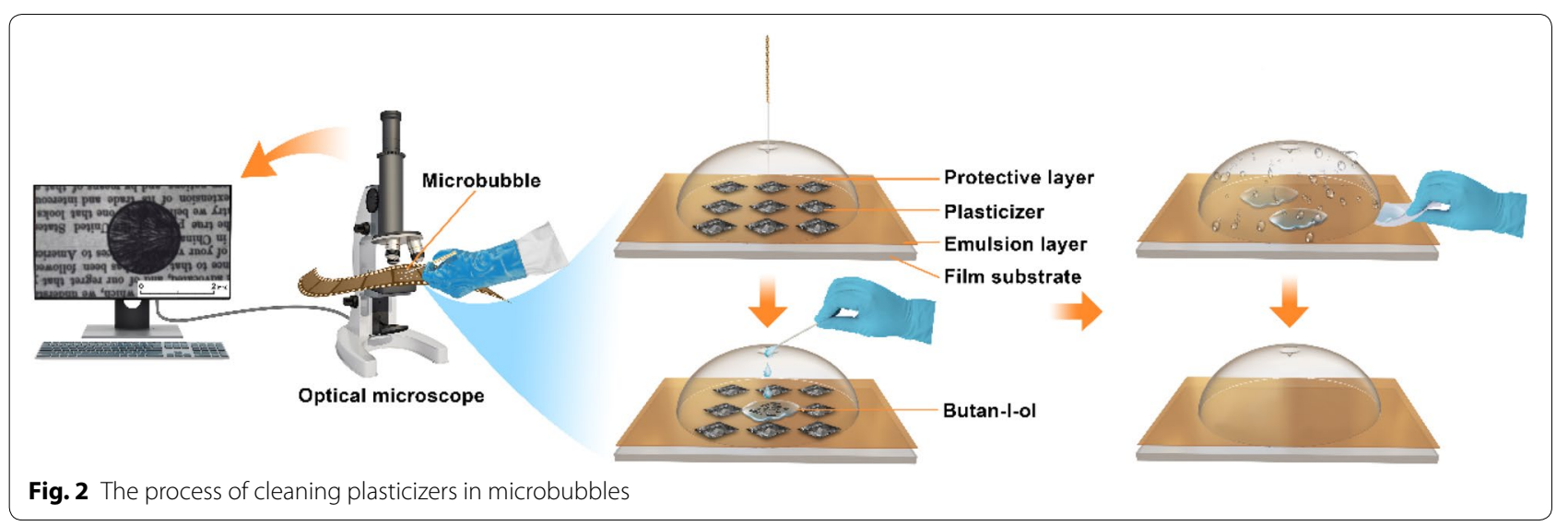


specimens was undertaken using the following parameters: $40{ }^{\circ} \mathrm{C}, 60 \%$ relative humidity $(\mathrm{RH})$ for 21 days. The UV accelerated aging was performed at $50 \% \mathrm{RH}$ and $25^{\circ} \mathrm{C}$ for 21 days in a self-made UV aging box which used eight UV fluorescent lamps (UVA-340) as light sources according to ISO 4892-3:1994. The rated lamp was $40 \mathrm{~W}$, and its irradiance range was $0-1.0 \mathrm{w} / \mathrm{m}^{2}$. Then the specimens were kept at $(23 \pm 1){ }^{\circ} \mathrm{C}, \mathrm{RH}(50 \pm 2) \%$ for at least $24 \mathrm{~h}$ until the moisture equilibrium according to ISO 11093-2: 1994.

\section{Results and discussion}

\section{Removing of plasticizers in microbubble}

Figure 3 presents the optical images of a microbubble in a cellulose acetate film sample before and after the plasticizer was removed and its corresponding SEM image. It can be seen from Fig. 3a, b that once the plasticizer is cleaned using the combination of optical microscopy and the stainless-steel needle, the original image is revealed. Although the plasticizer was removed in some microbubbles, the image was not always clear and well defined. SEM was used to investigate the morphology of internal surface of the microbubble after removing the protective layer and plasticizer (Fig. 3c). The internal surface was observed to be rough likely due to the formation of microbubble.

Previous literature has confirmed that shortening the incident light pathway is the fundamental factor leading to blurring of the image [30]. From Fig. 3b, a number of small dark spots are observed inside the microbubble. The uneven interface in the microbubble increases light scattering as light passes through the film. Filling materials were selected to permeate inside the microbubble to reduce the scattering attributed to the rough interface and to investigate if this would improve the image quality.

\section{Conservation applications of EC}

Polymer materials are commonly used for the protection of cultural heritage objects [31]. Ethyl cellulose is the most commonly employed filling material and typically prepared as a solution by dissolving in butan-1-ol. As shown in Table 1, the 3\% butan-1-ol solution of EC has the shortest permeation time. The permeation time can be seen to increase with increasing concentrations of EC. Figure 4 presents the optical images of the interface using different concentrations of EC solutions. The clarity of the image improves with the application of the lower concentrations of EC solutions (Fig. 4b, c), and notably decreases with EC concentrations of more than $5 \%$ due to increased viscosity and decreased permeability (Fig. 4d, e). Based on these results, the $5 \%$ butan-1-ol solution of EC was selected as the filling material.

Accelerated ageing tests are used to study the longterm behavior of a variety of filling materials. Hydrolysis and oxidation are the main pathways for the degradation of filling materials [32-36]. Temperature, humidity and ultraviolet light were chosen as parameters to investigate the filling material durability (Fig. 5). Folding endurance and tensile strength are important indicators that characterize the mechanical properties of film [32]. The effects of dry heat, UV and hydrothermal aging on tensile strength and folding endurance of samples before and after treatment are shown in Fig. 5a, b. It can be seen that the tensile strength and folding endurance of treated samples increased by 1.5 and $2.8 \%$, respectively. The tensile strength of untreated samples decreased by 28.6, 16.9 and $40.3 \%$ after dry heat, UV and hydrothermal ageing 21 days, while treated samples decreased by $12.4,3.4$ and $23.9 \%$ respectively. The folding endurance of untreated samples decreased by $46.7,33.6$ and $56.1 \%$ after dry heat, UV and hydrothermal ageing after 21 days, while treated samples decreased by $30,12.7$ and $45.4 \%$ respectively. The tensile strength and folding endurance

Table 1 The concentration selection of filling material

\begin{tabular}{lllll}
\hline EC & \multicolumn{4}{l}{ Concentration } \\
\cline { 2 - 5 } & w. 3\% & w. 5\% & w. 7\% & w. 10\% \\
\hline Permeation time(s) & $<30$ & $30-50$ & $>60$ & $>100$ \\
\hline
\end{tabular}

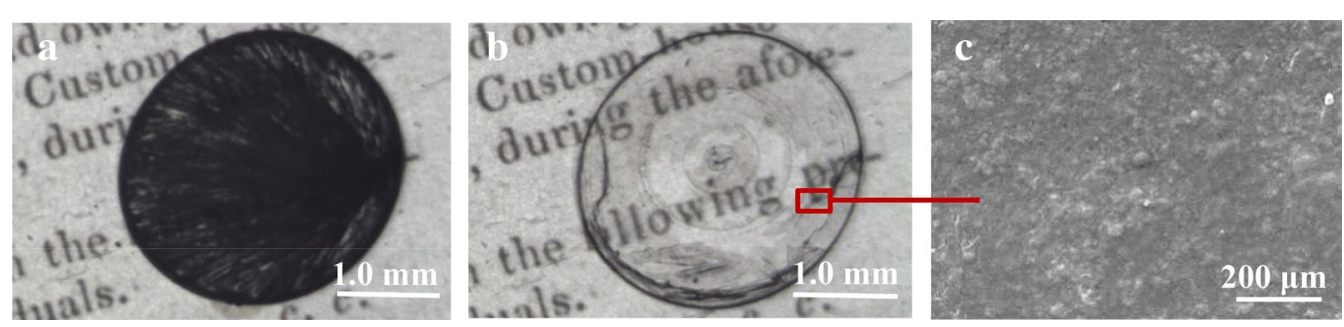

Fig. 3 Optical images of a microbubble before (a) and after (b) plasticizer was removed, as viewed with an optical microscopy using transmitted light; c SEM image of the internal surface after removal of the gelatin protective layer and plasticizer 

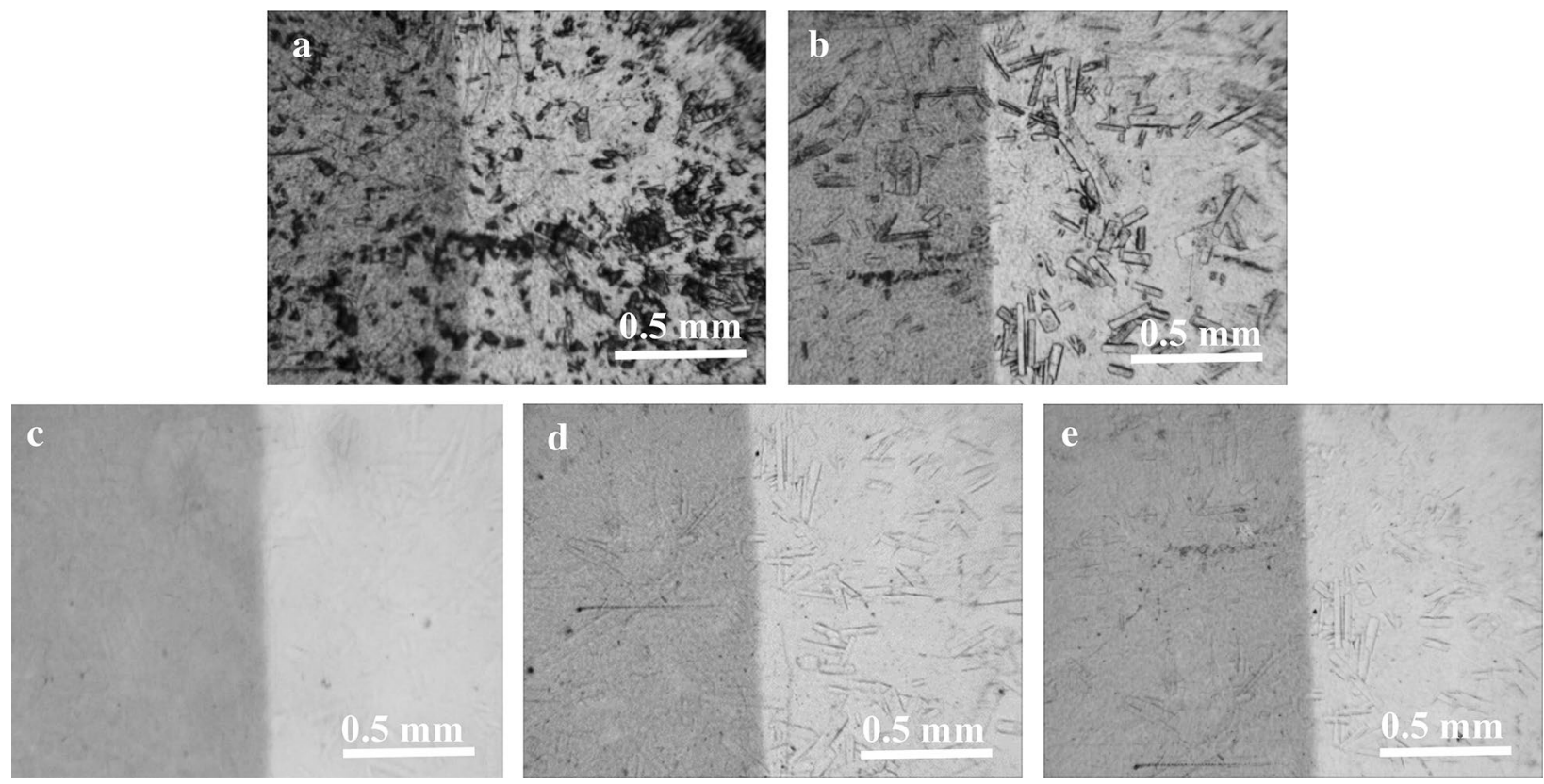

Fig. 4 Photos of the internal surface viewed with an optical microscopy using transmitted light: a unfilled rough interface; $\mathbf{b}$ filled interface with $3 \%$ $\mathrm{EC} ; \mathbf{c} 5 \% \mathrm{EC} ; \mathbf{d} 7 \% \mathrm{EC} ; \mathbf{e} 10 \% \mathrm{EC}$

properties of untreated samples significantly decreased after ageing compared to the treated samples. The effect of hydrothermal aging was greater than that of dry heat and ultraviolet exposure, implying that relative humidity and temperature are the main factors that influence aging. The treated samples exhibited a high level of stability to humidity, temperature and UV and a smaller loss of film strength compared to untreated samples. From Fig. 5c, it can be seen that the optical density did not changed before and after treatment with filling materials. The transmittance of the untreated samples decreased more than the treated samples with increasing aging. The result indicates that the filling materials have good durability over this time frame.

As outlined in the method displayed in Fig. 2, about $0.2 \mathrm{ml}$ of a $5 \% \mathrm{EC}$ in butan-1-ol was used as a filling material and was infiltrated into the interior of the cleaned microbubble to obtain a clearer image (Fig. 6a). The SEM image of the interface shows a uniform and flat surface (Fig. 6b). It is proposed that the filling materials form an EC film that adheres to the rough surface of the microbubble. In addition, the difference between the refractive index of the rough interfacial particles and filling materials decreases leading to less light scattering and enhancing the clarity of the image [30].

The Keyence VK-X250K shape analysis and confocal microscope were used to characterize the internal surface morphology and roughness of the microbubbles before and after the addition of filling materials. Surface geometric features are described by morphology parameters. The most commonly used parameter is surface roughness, which is represented by the contour curve of a section on the surface [37]. The smaller the surface roughness value the smoother the surface. As shown in Fig. 7, the internal surface of the microbubble after cleaning had a morphology with significant fluctuations with the height varying from 18.51-45.52 $\mu \mathrm{m}$, while it was relatively uniform and smooth after filling with the height of -2.46 to $8.13 \mu \mathrm{m}$. The sample surface roughness parameters were measured using Keyence software VK-H1XAC and after corrections the measured area was $\sim 268 \times 358 \mu \mathrm{m}$ as shown in Table 2 . The measured mean surface arithmetical height $\left(\mathrm{S}_{\mathrm{a}}\right)$ of the internal interface of microbubble after cleaning was $0.971 \mu \mathrm{m}$, which was found to reduce to $0.367 \mu \mathrm{m}$ after it was filled. $\mathrm{S}_{\mathrm{a}}$ decreased by $62.2 \%$ in treated samples compared to those untreated samples. The maximum height $\left(\mathrm{S}_{\mathrm{z}}\right)$ at the internal surface of microbubble was $27.014 \mu \mathrm{m}$ after cleaning, while it decreased to $10.589 \mu \mathrm{m}$ after filling. The ratio of height to width of surface properties $\left(S_{t r}\right)$ of the microbubble interface was 0.612 , decreasing to 0.172 after filling. $S_{\text {tr }}$ is closer to 0 , indicating the smoother surface, while it is closer to 1 , indicating that the rougher surface. The experimental results are further confirmation that the internal surface of microbubble is not uniform. The arithmetic means peak curvature $\left(\mathrm{S}_{\mathrm{pc}}\right)$ of the 

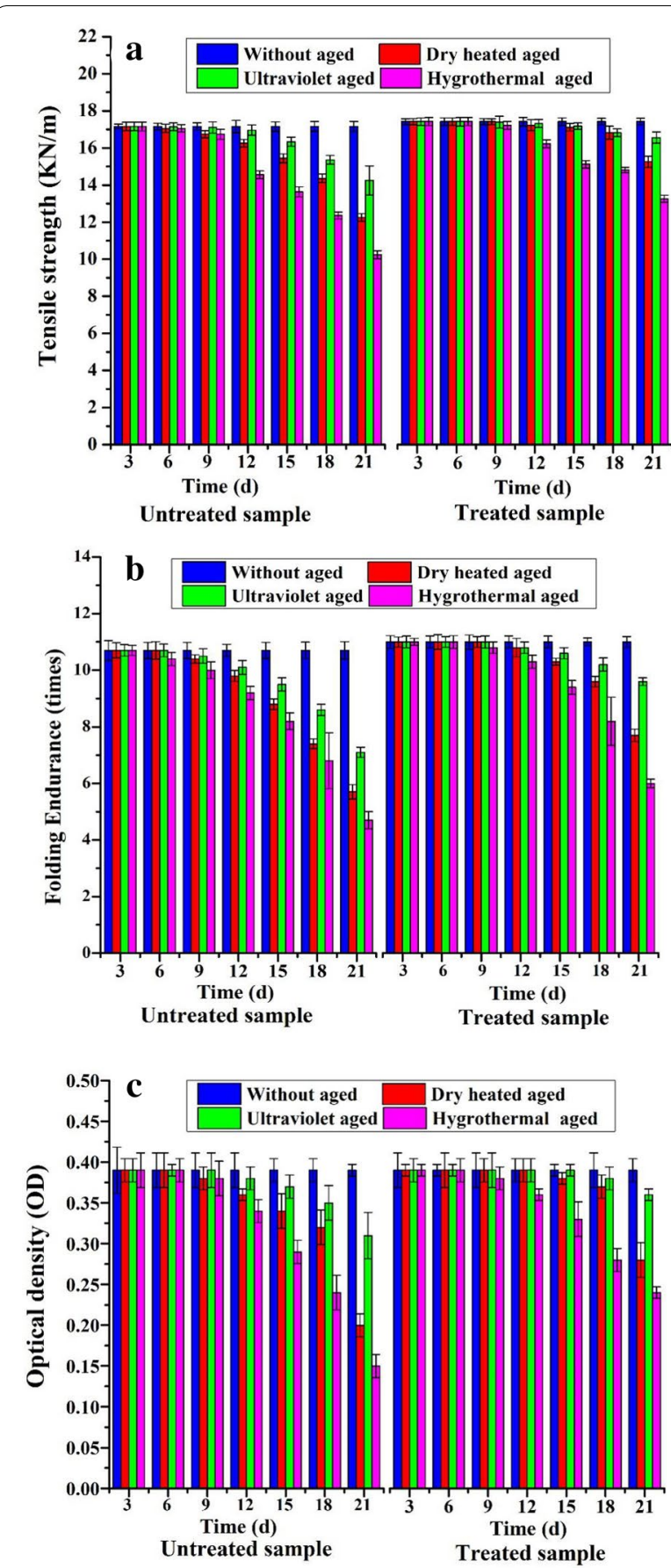

Fig. 5 a Tensile strength; $\mathbf{b}$ Folding endurance; c Optical density

internal surface of microbubble was $4167.165 \mathrm{~mm}^{-1}$ after cleaning, whereas it was reduced to $1299.603 \mathrm{~mm}^{-1}$ after filling, indicating that the sharpness of surface peaks is reduced. The area ratio of interface expansion $\left(\mathrm{S}_{\mathrm{dr}}\right)$ of microbubble interface is 0.455 after cleaned, whereas it

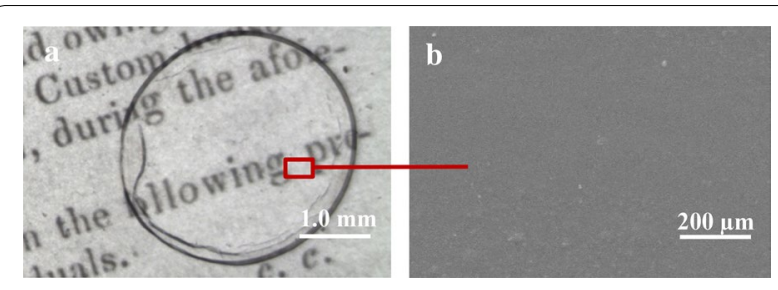

Fig. 6 Optical images showing the effect of filling material viewed with an optical microscope using transmitted light: $\mathbf{a}$ image of microbubble after being filled with a 5\% EC solution; b SEM image of the internal surface of the same microbubble

decreases to 0.076 after filling. Based on the above findings the results confirm that the internal surface of the cleaned microbubble is more uniform and smoother.

The light scattering characteristics of the rough inner surface of the microbubble are directly related to reflectivity, which can be measured by surface reflectivity using visible light [38]. Figure 8 shows that the reflectivity of the internal surface of the microbubble after cleaning is greater than that of the filled surface. The combined results shown in Fig. 7 and 8, reveal that the internal surface of microbubble is very rough after cleaning, promoting the diffuse reflection of visible light.

On the basis of this analysis, the following mechanism of action of the effect of the filling materials is proposed and is supported by the corresponding schematic illustration in Fig. 9. The image when observed using optical microscopy is effected by transmission of light. The typical diameter of a microbubble is $0.5-2 \mathrm{~mm}$ and it is filled with plasticizer crystals. The observed black dots results because visible light is being reflected by the microbubble. The inner surface of the microbubble is rough after the plasticizer cleaned, leading to increased diffuse reflection and resulting in blurred images. This phenomenon can be explained by the theory of light scattering whereby the rough surface scatters the incident light [39]. The scattering shortens the pathlength of the incident light and weakens the transmitted light, resulting in an unclear image and black spots [40,41]. The refractive index difference between the space and filling material is decreased when filling materials of higher refractive index are used to treat the microbubble. The light scattering is decreased significantly, increasing the amount of transmitted light.

\section{Conclusion}

In summary, a method to treat microbubble disease was investigated using a combination of stainlesssteel needle and optical microscopy for the first time. 

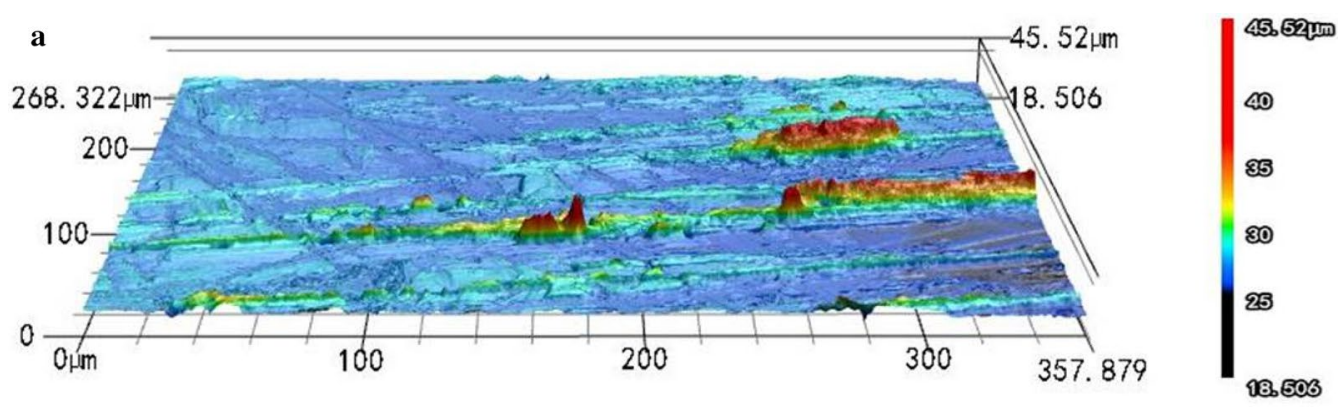

b

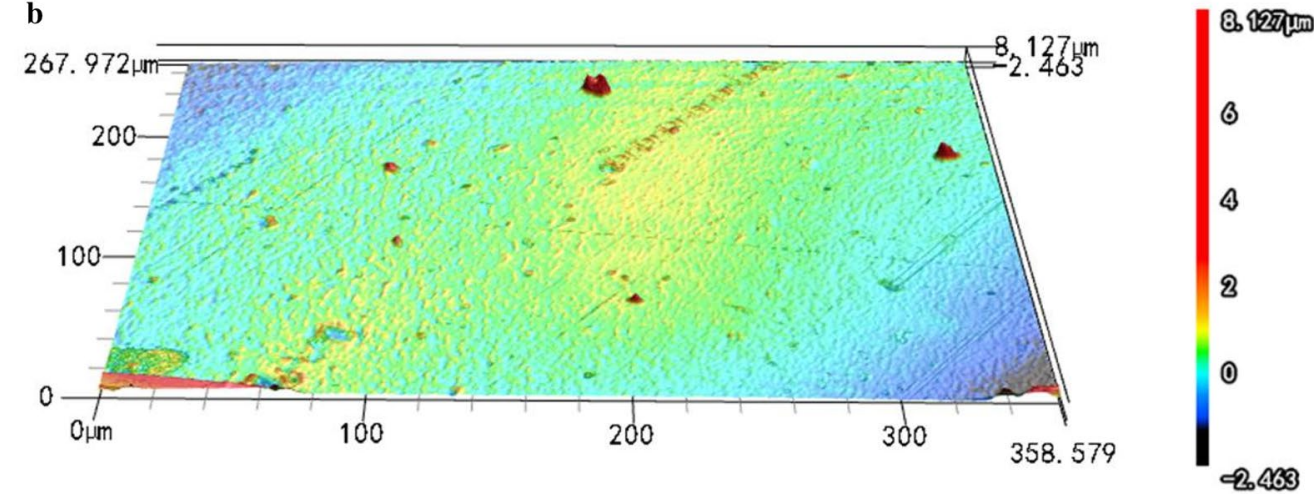

Fig. 7 3D morphology viewed with confocal microscopy of microbubble after cleaning (a) and after the addition of filling material (b)

Table 2 Surface roughness test results of film performed before (a) and after (b) the addition of filling materials

\begin{tabular}{lcllll}
\hline & $\mathbf{S}_{\mathbf{a}}(\boldsymbol{\mu m})$ & $\mathbf{S}_{\mathbf{z}}(\boldsymbol{\mu m})$ & $\mathbf{S}_{\mathbf{t r}}(\mathbf{1} / \mathbf{m m})$ & $\mathbf{S}_{\mathbf{p c}}$ & $\mathbf{S}_{\mathbf{d r}}$ \\
\hline $\mathrm{a}$ & 0.971 & 27.014 & 0.612 & 4167.165 & 0.455 \\
$\mathrm{~b}$ & 0.367 & 10.589 & 0.172 & 1299.603 & 0.076 \\
$\begin{array}{l}\text { Relative } \\
\begin{array}{l}\text { decrease } \\
(\%)\end{array}\end{array}$ & 62.2 & 60.8 & 71.9 & 68.8 & 83.3 \\
\hline
\end{tabular}

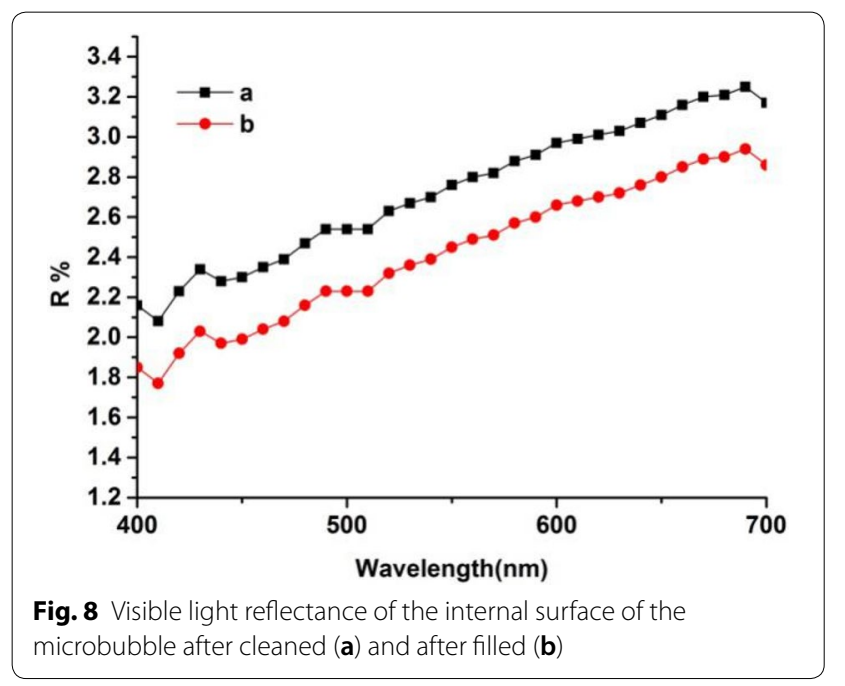

This method was successfully used to allow infiltration of butan-1-ol into the microbubble. Plasticizer crystals were effectively removed during repeated physical pressing of the outer protective microbubble layer with a cotton swab dipped in butan-1-ol. The morphology and roughness of the microbubble surface were characteristic using SEM and confocal microscopy and it was found that the unclear image was caused by light scattering from the rough surface interface. A 5\% butan-1-ol solution of ethyl cellulose was used to fill the microbubble interior to obtain a clearer image. The age resistance of the ethyl cellulose filling material was evaluated using dry heat, hygrothermal and UV accelerated aging. The degradation of the film mechanical properties after artificial aging was measured by tensile strength, folding endurance tests and optical density, and it was found that the filling material had good durability. Findings from a comparative study on the roughness and reflectivity of the internal surface of the microbubble before and after filling, allows us to propose that the light scattering phenomenon of the rough interface inside the microbubble is the main reason for the blurry image. The high refractive index of the filling liquid reduces the light scattering phenomenon to obtain a clear image information. 


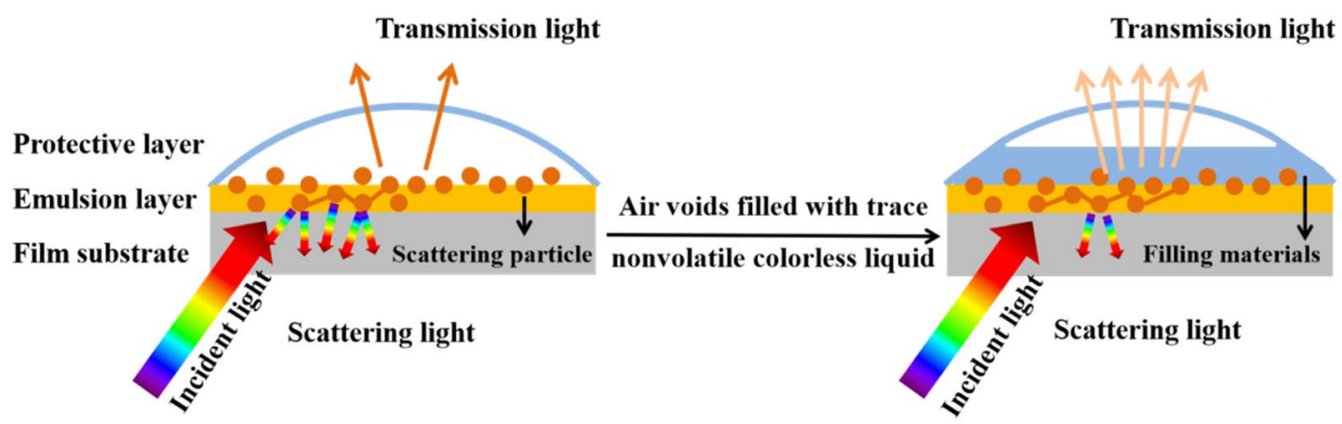

Fig. 9 Schematic illustration outlining the mechanism of action and how the addition of filling materials reduce diffuse scattering of light

\section{Abbreviations}

SEM: Scanning electron microscopy; EC: Ethyl cellulose; UV: Ultraviolet.

\section{Acknowledgements}

This work was supported by the National Natural Science Foundation of China (Grant No. 22002080), Fundamental Research Funds for the Central Universities (Grant No. GK 201903049 and 201903054), Key Research and Development Program of Shaanxi Province, China (Grant No. 2020SF-358), and Science and Technology Project of Xi'an, China (Grant No. 2020KJRC0014)

\section{Authors' contributions}

ZJ designed the study. YQ and JL performed the measurements and contributed to the SEM and laser confocal microscopy analysis; ZJ, HX, YL, DH and $\mathrm{XC}$ wrote most of the initial versions of the text and figures. $\mathrm{XC}, \mathrm{HX}$ and $\mathrm{DH}$ analyzed the data. All authors contributed to research strategy, the discussion and interpretation of the results and to the final form of the text and figures. All authors read and approved the final manuscript.

\section{Funding}

The research is financially supported by National Natural Science Foundation of China (Grant No. 22002080), Fundamental Research Funds for the Central Universities (Grant No. GK 201903049 and 201903054), Key Research and Development Program of Shaanxi Province, China (Grant No. 2020SF-358), and Science and Technology Project of Xi'an, China (Grant No. 2020KJRC0014).

\section{Availability of data and material}

The data sets analyzed during the current study are available from the corresponding author on reasonable request.

\section{Competing interests}

The authors declare that they have no conflict of interest.

Received: 16 May 2020 Accepted: 24 September 2020

Published online: 02 October 2020

\section{References}

1. Grattan DW. Saving the twentieth century: the conservation of modern materials, In: Proceedings of a conference symposium'91: saving the twentieth century, Ottawa, Canada, 15-20 September, 1991.

2. Shashoua Y. Inhibiting the inevitable: current approaches to slowing the deterioration of plastics. Macromol Symposia. 2006;238:67-77.

3. Mazurek J, Laganà A, Dion V, Etyemez S, Carta C, Schilling MR. Investigation of cellulose nitrate and cellulose acetate plastics in museum collections using ion chromatography and size exclusion chromatography. J Cult Herit. 2019;35:263-70.

4. Adelstein PZ, Reilly JM, Nishimura DW, Erbland CJ, Bigourdan JL. Stability of cellulose ester substrate photographic film: part V: recent findings. SMPTE J. 1995:104:439-47.
5. Schilling M, Bouchard M, Khanjian H, Learner T, Phenix A, Rivenc R. Application of chemical and thermal analysis methods for studying cellulose ester plastics. Acc Chem Res. 2010;43:888-96.

6. Shashoua Y. Conservation of plastics: materials science, degradation and preservation. J Am Inst Conserv. 2010;49:55-7.

7. Tsang J, Madden O, Coughlin M, Maiorana A, Watson J, Little NC, Speakman RJ. Degradation of 'lumarith' cellulose acetate: Examination and chemical analysis of a salesman's sample kit. Stud Conserv. 2009;2:90-105.

8. Littlejohn D, Pethrick RA, Quye A, Ballany JM. Investigation of the degradation of cellulose acetate museum artefacts. Polym Degrad Stab. 2013:98:416-24.

9. Sutherland K, Schwarzinger C, Price BA. The application of pyrolysis gas chromatography mass spectrometry for the identification of degraded early plastics in a sculpture by Naum Gabo. J Anal Appl Pyrol. 2012;94:202-8.

10. Allen NS, Edge M, Jewitt TS. Degradation and stabilization of cellulose triacetate base motion-picture film. J Imaging Sci Technol. 1992;36:4-12.

11. Ayuk JE, Mathew AP, Oksman K. The effect of plasticizer and cellulose nanowhisker content on the dispersion and properties of cellulose acetate butyrate nanocomposites. J Appl Polym Sci. 2009;114:2723-30.

12. Richardson E, Giachet MT, Schilling M, Learner T. Assessing the physical stability of archival cellulose acetate films by monitoring plasticizer loss. Polym Degrad Stab. 2014;107:231-6.

13. Quintana R, Persenaire O, Lemmouchi Y, Sampson J, Martin S, Bonnaud L, Dubois P. Enhancement of cellulose acetate degradation under accelerated weathering by plasticization with eco-friendly plasticizers. Polym Degrad Stab. 2013;98:1556-622.

14. Ballany J, Littlejohn D, Pethrick RA, Quye A. Probing the factors that control degradation in museum collections of cellulose acetate artefacts, Historic Textiles, Papers, and Polymers. Museums. 2001;Chapter 12:14565. https://doi.org/10.1021/bk-2001-0779.ch012.

15. Jia ZH, Li YH, Qi YP, Zhou YJ, Hu DD, Chao XL, Xing HP, Li J. Study on microbubble of cellulose acetate microfilm of the Republic of China (AD 1912-1949) collected in the Second Historical Archives of China, Heritage Science. 2020; 8: 29-38

16. National film preservation foundation contributors. The film preservation guide: The basics for archives, libraries, and museums [M]. San francisco: National Film Preservation Foundation; 2004.

17. Melville A, Simmon S. Film preservation 1993: A study of the current state of American film preservation[M]. New York: Library of congress; 1993.

18. Sadhar SI, Rajagopalan AN. Restoration of scanned photographic images. Signal Processing. 2006;5:1035-48.

19. Takahiro Y, Tatsuya F, Mitsuru N, Daisuke S, Kazuhiro S, Tetsuro F. Superhigh-definition digital cinema distribution system with 8-Million-Pixel resolution. Syst Comput Japan. 2006;4:35-44.

20. Kokaram A. Detection and removal of line dcratches in degraded motion picture sequences. Signal Processing. 1996;1:5-8.

21. Qi YP, Zhou YJ, Zhang J, Huo YJ, Shen SK, Li YH. Research on the influence of acetic acid syndrome on the property of film substrate. J Shaanxi Normal Univ. 2017;2:63-7 (in Chinese).

22. Zhou YJ, Li YH, He Y, Qin XL, Zuo CX. Discussion on storage conditions of cellulose acetate cine-film. Arch Sci Study. 2010;4:66-9 (in Chinese). 
23. Jia ZH, Li YH, Shi MR, Xie LN, Zhou YJ. The effect of temperature and humidity on the physical properties of cellulose acetate film. Imaging Sci Photochem. 2017:6:797-807.

24. Zhou YJ, Zhang J, Qi YP, Li YH, He Y. Analyze and characterize the crystal precipitation from the acetic acid syndrome cine-film. Image Technol. 2015;5:60-4 (in Chinese)

25. Y.H. Li, Y.J. Zhou. Application of alcohols in cleaning triphenyl phosphate on film surface [P].China Patent: ZL201110366939.6. 2012-12-5.

26. Rekhi GS, Jambhekar SS. Ethylcellulose - A Polymer Review. Drug Dev Ind Pharm. 1995;21:61-7.

27. Rekhi GS, Jambhekar SS. Ethylcellulose a polymer review. Drug Dev Ind Pharm. 1995:1:61-77.

28. Hughes NE, Marangoni AG, Wright AJ. Potential food applications of edible oil organogels. Trends Food Sci Technol. 2009;10:470-80.

29. Zetzl AK, Marangoni AG, Barbut S. Mechanical properties of ethylcellulose oleogels and their potential for saturated fat reduction in frankfurters. Food Funct. 2012;3:327-37.

30. Zheng LZ, Liang XT, Li SR, Li YH, Hu DD. Fading and showing mechanisms of ancient color relics based on light scattering induced by particles. RSC Adv. 2018:8:1124-31.

31. Ploeger R, Rie ER, McGlinchey CW, Palmer M, Maines CA, Chiantore O. The long-term stability of a popular heat-seal adhesive for the conservation of painted cultural objects. Polym Degrad Stab. 2014;107:307-13.

32. Gauthier E, Laycock B, Cuoq FM, Halley PJ, George KA. Correlation between chain microstructural changes and embrittlement of LLDPEbased films during photo- and thermo-oxidative degradation. Polym Degrad Stab. 2013;98:425-35.

33. Kolar J, Strlic M, Pentzien S, Kautek W. Near-UV, visible and IR pulsed laser light interaction with cellulose. Appl Phys A Mater Processing. 2000;71:87-90.
34. Bukovsky V, Trnková M. The inflfluence of secondary chromophores on the light induced oxidation of paper part II: the inflluence of light on groundwood paper. Restaurator. 2003;24:118-32.

35. Hon NS. Formation of free radicals in photoirradiated cellulose. I. Effect of wavelength. J Polym Sci Polym Chem Edition. 1975;13:1347-61.

36. Phillips GO, Hinojosa O, Arthur JC, Mares T. Photochemical initiation of free radicals in cotton cellulose. Text Res J. 1966;36:822-7.

37. Klauer K, Eifler M, Seewig J, Kirsch B, Aurich JC. Application of functionoriented roughness parameters using confocal microscopy. Eng Sci Technol. 2018;3:302-13.

38. Cuppo FLS, Garci'a-Valenzuela A, Olivares JA. Influence of surface roughness on the diffuse to near-normal viewing reflectance factor of coatings and its consequences on color measurements. Color Res Appl. 2013;3:177-87.

39. Osterhold M. Influence of substrate structure on coating appearance and the relevant characterization methods. Materialwiss Werkstofftech. 1998;29:131-6.

40. Simonot L, Elias M. Color change due to surface state modification. Color Res Appl. 2003;28:45-9.

41. Torrance KE, Sparrow EM. Theory for off-specular reflection from roughened surfaces. J Opt Soc Am B. 1967;57:1105-14.

\section{Publisher's Note}

Springer Nature remains neutral with regard to jurisdictional claims in published maps and institutional affiliations.

\section{Submit your manuscript to a SpringerOpen ${ }^{\circ}$ journal and benefit from:}

- Convenient online submission

- Rigorous peer review

- Open access: articles freely available online

- High visibility within the field

- Retaining the copyright to your article

Submit your next manuscript at $\boldsymbol{\nabla}$ springeropen.com 